\title{
Efficacy of a novel topical combination of esafoxolaner, eprinomectin and praziquantel against ear mite (Otodectes cynotis) infestations in cats
}

Eric Tielemans ${ }^{1, *}$, Joe Prullage ${ }^{3}$, Otsuki Tomoko ${ }^{4}$, Julian Liebenberg ${ }^{5}$, Balázs Capári ${ }^{6}$, Smaragda Sotiraki ${ }^{7}$, Despoina Kostopoulou ${ }^{7}$, Panagiota Ligda ${ }^{7}$, Michael Ulrich ${ }^{8}$, and Martin Knaus ${ }^{2}$

${ }^{1}$ Boehringer-Ingelheim Animal Health, 29 Avenue Tony Garnier, 69007 Lyon, France

2 Boehringer-Ingelheim Vetmedica GmbH, Kathrinenhof Research Center, Walchenseestr. 8-12, 83101 Rohrdorf, Germany

${ }^{3}$ Boehringer-Ingelheim Animal Health, Missouri Research Center, 6498 Jade Rd., Fulton, 65251 MO, USA

${ }^{4}$ Boehringer Ingelheim Animal Health Japan Co Ltd, ThinkPark Tower, 2-1-1 Osaki, Shinagawa-ku, 141-6017 Tokyo, Japan

${ }^{5}$ Clinvet International (Pty) Ltd., P.O. Box 11186, Universitas, 9321 Bloemfontein, Republic of South Africa

${ }^{6}$ Kapriol Bt., Vak Bottyán St. 1, 8330 Sümeg, Hungary

7 Veterinary Research Institute, ELGO-DIMITRA Campus, Thermi, 57001 Thessaloniki, Greece

${ }^{8}$ Cheri-Hill Kennel \& Supply Inc., 17190 Polk Rd., Stanwood, 49346 MI, USA

Received 17 February 2020, Accepted 8 March 2021, Published online 2 April 2021

\begin{abstract}
Esafoxolaner, a purified enantiomer of afoxolaner with insecticidal and acaricidal properties, is combined with eprinomectin and praziquantel, nematodicidal and cestodicidal compounds, in NexGard ${ }^{\circledR}$ Combo, a novel topical endectoparasiticide formulation for cats. The efficacy of this formulation was assessed against Otodectes cynotis in two laboratory studies conducted in South Africa and in the USA with local isolates, and in one field trial conducted in Europe. In each study, cats were randomly allocated to a placebo-treated control group and a novel formulation-treated group. In the laboratory studies, cats were treated at the minimum recommended dose; in the field trial, cats were treated at label dose. All included cats were diagnosed positive for $O$. cynotis prior to treatment by otoscopy. The main variable of efficacy was a comparison of the number of live $O$. cynotis collected in both ear canals of all cats in the treated and control groups, one month after treatment. Efficacy of the novel topical formulation exceeded $97 \%$ in the three studies. These studies demonstrated the high effectiveness of NexGard ${ }^{\circledR}$ Combo in cats for the treatment of $O$. cynotis infestations. No health abnormalities were attributed to the treatment in any of the studies.
\end{abstract}

Key words: Cat, Ear mite, Otodectes cynotis, Esafoxolaner, Efficacy.

Résumé - Efficacité d'une nouvelle association topique d'esafoxolaner, d'éprinomectine et de praziquantel contre les infestations par l'acarien agent de la gale des oreilles Otodectes cynotis chez les chats. L'esafoxolaner, un énantiomère purifié d'afoxolaner aux propriétés insecticides et acaricides, est associé à l'éprinomectine et au praziquantel, composés nématodicides et cestodicides, dans NexGard ${ }^{\circledR}$ Combo, une nouvelle formulation endectoparasiticide topique pour chats. L'efficacité de cette formulation a été évaluée contre Otodectes cynotis dans deux études de laboratoire menées en Afrique du Sud et aux États-Unis avec des isolats locaux, et dans un essai sur le terrain mené en Europe. Dans chaque étude, les chats ont été répartis au hasard entre un groupe témoin traité par placebo et un groupe traité par la nouvelle formulation. Dans les études de laboratoire, les chats ont été traités à la dose minimale recommandée, et dans l'essai sur le terrain, les chats ont été traités à la dose indiquée sur l'étiquette. Tous les chats inclus ont été diagnostiqués positifs pour $O$. cynotis avant le traitement par otoscopie. La principale variable d'efficacité était une comparaison du nombre d'O. cynotis vivants, collectés dans les deux conduits auditifs de tous les chats, dans le groupe traité et dans le groupe témoin, un mois après le traitement. L'efficacité de la nouvelle formulation topique a dépassé $97 \%$ dans les trois études. Ces études ont démontré la grande efficacité de NexGard ${ }^{\circledR}$ Combo chez les chats pour le traitement des infestations par O. cynotis. Aucune anomalie de santé n'a été attribuée au traitement dans aucune des études.

*Corresponding author: eric.tielemans@boehringer-ingelheim.com

Special Issue - NexGard ${ }^{\circledR}$ Combo (esafoxolaner, eprinomectin, praziquantel): A new endectocide spot-on formulation for cats. Invited Editor: Frédéric Beugnet

This is an Open Access article distributed under the terms of the Creative Commons Attribution License (https://creativecommons.org/licenses/by/4.0), which permits unrestricted use, distribution, and reproduction in any medium, provided the original work is properly cited. 


\section{Introduction}

The ear mite Otodectes cynotis is one of the major ectoparasites of cats and a primary cause of otitis externa [13, 33]. In a multi-centric survey conducted on domestic cats randomly presented in veterinary clinics for reasons unrelated to parasitic disease, in seven countries in Southern and Central Europe, ear mites were diagnosed in $17.4 \%$ of 1519 cats [4]. In another survey conducted in Greece, $25.5 \%$ of domestic cats were diagnosed ear mite-positive [27]. In this study, mites were found especially in kittens and roaming animals. Otodectes cynotis is pathogenic in young cats, dogs and ferrets, and is directly transmitted from one animal to another [19, 23]. It was identified as the primary cause of otitis externa in $53.3 \%$ of 187 stray cats [20]. Otodectes cynotis can also go unnoticed at an early stage: $14 \%$ of kittens up to 6 months in urban areas in Greece were diagnosed ear mite-positive without signs of otitis externa [17]. The correlation between clinical signs and number of O. cynotis can be inconsistent: one or two mites have been seen to cause severe otitis lesions with large amounts of dark cerumen, while 50 to 100 mites have been found in clean ear canals [8].

At clinical examination, O. cynotis infested ear canals typically reveal erythema and dark brown cerumen. Adult mites, moving white organisms of $0.3-0.5 \mathrm{~mm}$ can be visible with the naked eye by otoscopy or on swabs of cerumen and debris from ear canals. Occasionally, the infestation leads to intense irritation and secondary bacterial and/or fungal infection. Otohematoma is also a common consequence of such infestation in cats [8, 20, 22, 27].

Several curative treatments are available, mainly in the form of a macrocyclic lactone topical endectocide [3, 10, 12, 24, 25]. Preventive treatment with a topical formulation containing fipronil, (S)-methoprene, eprinomectin and praziquantel has also been demonstrated [5]. More recently, the isoxazoline class of compounds has brought new curative solutions against mites. Afoxolaner efficacy has been demonstrated against Sarcoptes, Demodex and Otodectes infestations in dogs [6, 7, 9, 14, 16]. In cats, fluralaner, another isoxazoline compound was demonstrated efficacious against $O$. cynotis infestations in cats alone or in combination with moxidectin [28], as well as sarolaner, alone or in combination with selamectin $[1,26]$. Off-label use of oral afoxolaner, a dog-only product (Nexgard ${ }^{\circledR}$ ), has been found to be efficacious against $O$. cynotis infestations in cats [18].

Esafoxolaner is the purified and active (S)-enantiomer of afoxolaner, a novel compound with insecticidal and acaricidal properties. NexGard ${ }^{\circledR}$ Combo, a novel topical combination of esafoxolaner, eprinomectin and praziquantel was developed for cats with the aim of offering a wide spectrum of antiparasitic activity.

This article describes three studies performed to assess the efficacy in cats of one application of the novel esafoxolaner, eprinomectin and praziquantel formulation for the treatment of $O$. cynotis infestations. Two studies were run under laboratory conditions with induced or natural infestation models, respectively in South Africa and in the United States; one study was run on naturally infested domestic cats in the field, in Hungary and Greece.

\section{Materials and methods Ethics}

The study protocols were reviewed and approved by the Sponsor's and local Institutional Animal Care and Use Committees. Cats were managed and handled with due regard for their wellbeing.

\section{Study designs}

The three studies were conducted in accordance with Good Clinical Practices as described in International Cooperation on Harmonization of Technical Requirements for Registration of Veterinary Medicinal Products (VICH) guideline GL9.

The three studies were conducted under a negativecontrolled and randomized design, with cats randomly allocated to two groups, a novel formulation-treated group, and a placebo-treated group.

The $O$. cynotis efficacy assessment was based on comparison of live mites counted in the ear canals of negative control and treated animals one month after treatment.

Personnel involved with evaluation of safety and efficacy, and the owners in the field study, were unaware as to treatment assignments.

The main differences in context and design of the three studies are summarized in Table 1.

\section{Ear mite infestation models}

In Lab \#1, with an induced infestation model, mites were harvested from local donor cats naturally infested with Otodectes. Mites were collected by ear flushing and approximately 100 mites were directly transferred into each ear canal of the study cats, under light sedation. Adequate infestation was confirmed by otoscopical assessment when live mites had established in both ear canals. The study was run in three phases as adequate numbers of cats were diagnosed infested. The duration between infestation and treatment was 5, 10 and 16 weeks, respectively.

In Lab \#2 and the Field study, with natural infestation models, Otodectes naturally infested cats were selected on the basis of positive ear mite diagnosis by otoscopical observation.

\section{Treatment}

Cats were treated once on Day 0. The treatments were applied directly to the skin, after parting the hair, on one spot in the midline of the neck between the base of the skull and the shoulder blades.

In the laboratory studies, cats assigned to the placebo control group were treated with mineral oil at $0.12 \mathrm{~mL} / \mathrm{kg}$. Cats assigned to the treated group received a topical application of the novel formulation at the minimum recommended dose of $0.12 \mathrm{~mL} / \mathrm{kg}$, delivering $1.44 \mathrm{mg} / \mathrm{kg}$ esafoxolaner, $0.48 \mathrm{mg} / \mathrm{kg}$ eprinomectin and $10.0 \mathrm{mg} / \mathrm{kg}$ praziquantel. Lab \#1 was performed at an early stage of product development, using an experimental formulation with identical concentration and composition of active ingredients, but with some differences in the solvent system, in 
Table 1. Study contexts and designs.

\begin{tabular}{|c|c|c|c|}
\hline Studies & Lab \#1 & Lab \#2 & Field \\
\hline Model & Induced infestation & Natural infestation & Natural infestation \\
\hline Location/date & $\begin{array}{c}\text { South Africa/Dec } 2015 \text { - } \\
\text { March } 2016\end{array}$ & $\begin{array}{c}\text { Michigan, USA/Dec } 2018 \text { - } \\
\text { Jan } 2019\end{array}$ & Europe/Oct 2018 - Apr 2019 \\
\hline O. cynotis strain origin & South Africa & USA & Hungary and Greece \\
\hline Variable used for randomization & Bodyweight & $\begin{array}{l}\text { Pre-treatment otoscopic live } \\
\text { mite count }\end{array}$ & Order of presentation \\
\hline Inlusion criteria & $\begin{array}{l}\text { Both ear canals positive for } \\
\text { mites }\end{array}$ & $\begin{array}{l}\text { Both ear canals positive for } \\
\text { mites }\end{array}$ & $\begin{array}{c}\text { At least } 1 \text { motile ear mite in } 1 \\
\text { ear canal }\end{array}$ \\
\hline Number of treated/control cats & $8 / 8$ & $10 / 10$ & $32 / 33$ sentinels*, $54 / 61$ total $*$ \\
\hline Treatment dose & Minimum dose of $0.12 \mathrm{~mL} / \mathrm{kg}$ & Minimum dose of $0.12 \mathrm{~mL} / \mathrm{kg}$ & Commercial dose \\
\hline Main variable of efficacy & $\begin{array}{c}\text { Live } O \text {. cynotis counts } \\
\text { collected in } \\
\text { ear canals, Day } 28\end{array}$ & $\begin{array}{c}\text { Live } O \text {. cynotis counts } \\
\text { collected } \\
\text { in ear canals, Day } 32\end{array}$ & $\begin{array}{c}\text { Live } O \text {. cynotis counts } \\
\text { collected in ear } \\
\text { canals of sentinel animals, } \\
\text { Day } 30( \pm 3)\end{array}$ \\
\hline Secondary efficacy evaluations & $\begin{array}{c}\text { Otoscopic assessment } \\
\text { (scoring of debris/cerumen } \\
\text { and live mites), Days }-7,7 \text {, } \\
14,21,28\end{array}$ & None & $\begin{array}{c}\text { Otoscopic assessment } \\
\text { (scoring of pruritus and } \\
\text { quality/quantity of cerumen), } \\
\text { Day 0, Day } 30( \pm 3)\end{array}$ \\
\hline
\end{tabular}

* In the field trial, all cats in a household (total) were treated, one cat per household (sentinel) was evaluated for efficacy and safety, all other cats for safety.

comparison to the final novel formulation which was defined later, and used in Lab \#2 and in the Field study.

In the Field study, cats assigned to the treated group received a topical application of $\mathrm{NexGard}^{\circledR}$ Combo in the commercial applicator, at the recommended label dose of $0.3 \mathrm{~mL} / 0.8$ to $<2.5 \mathrm{~kg}$, or $0.9 \mathrm{~mL} / 2.5$ to $<7.5 \mathrm{~kg}$, delivering $1.44-4.5 \mathrm{mg} / \mathrm{kg}$ esafoxolaner, $0.48-1.50 \mathrm{mg} / \mathrm{kg}$ eprinomectin and $10.0-31.1 \mathrm{mg} / \mathrm{kg}$ praziquantel; cats assigned to the control group were treated with mineral oil at $0.3 \mathrm{~mL} / 0.8$ to $<2.5 \mathrm{~kg}$, or $0.9 \mathrm{~mL} / 2.5$ to $<7.5 \mathrm{~kg}$.

\section{Ear mite counts and ear mite level assessments}

In the three studies, a quantitative assessment of ear mites by ear canal mite collection was performed one month after treatment, under sedation. Ear canal content collection was performed by swabbing with cotton buds, and/or by filling with an aqueous solution to melt the ear canal content until clean. The swabbed materials and melted solutions were collected and drained into a sieve. The materials were examined for live mite identification and count, counts included immature and adult forms.

In Lab \#1, semi-quantitative ear mite level assessment was also performed weekly via otoscopical examination, as a secondary objective.

\section{Otoscopical and clinical examinations for otitis signs}

Otoscopical and clinical examinations for otitis signs were performed in Lab \#1, and the Field study.

The scoring system used for otoscopical and clinical assessments is described in Table 2.

In Lab \#1, otoscopical examinations were performed before treatment and on Days 7, 14, 21 and 28 (before the ear canal content collection procedure) for ear mite and debris/cerumen level assessments. In Lab \#2, no otoscopical examinations were performed for otitis signs. In the field study, otoscopical examinations were performed on Days 0 and 30 (before ear canal collection) for debris/cerumen and pruritus level assessment.

\section{Statistical analysis}

In the three studies, to compute percent $O$. cynotis efficacy, the geometric means of the total of adult and immature live mite counts in both ear canals were calculated by group. The geometric means were computed by taking the anti-logarithm of the average of the $\log$ (mite count +1$)$ and then subtracting 1 . Percent effectiveness with respect to the control group was calculated using the formula $([C-T] / C) \times 100$, where $C=$ geometric mean for the control group, and $T=$ geometric mean for the treated group.

The log-counts of the treated group were compared to the log-counts of the control group using an $F$-test adjusted for the allocation blocks used to randomize the animals to the treatment groups. The MIXED procedure in SAS Version 9.4 was used for the analysis, with treatment group listed as a fixed effect and the allocation blocks listed as a random effect. All testing was two-sided at $\alpha=0.05$ significance level. Lab \#1 was conducted using three phases. The effect of the phases was evaluated by modifying the above analysis of the logarithm of the total mite counts +1 in the Mixed procedure by adding phase and treatment-by-phase interaction as fixed effects.

\section{Results \\ Ear mite counts}

The results of ear mite counts following ear canal collections, one month after treatment, are summarized in Table 3. 
Table 2. Otoscopical and clinical scoring.

\begin{tabular}{lccc}
\hline & Ear mite level & Debris/Cerumen & Pruritus \\
\hline Score 0 & 0 mite & Normal, absent & Absent \\
Score 1 & $1-4$ mites & Clear, low volume & Mild, no skin alteration of external ear \\
Score 2 & $5-10$ mites & Brown, medium & volume \\
Score 3 & $>10$ mites & Dark, large volume & Marked, pronounced skin alteration of external ear \\
Applied in: & Lab \#1 & Lab \#1, field & Field \\
\hline
\end{tabular}

Table 3. Ear mite counts following ear canal flushing in Lab \#1, Lab \#2 and the Field study, one month after treatment.

\begin{tabular}{|c|c|c|c|c|c|c|}
\hline & \multicolumn{2}{|c|}{ Control group } & \multicolumn{2}{|c|}{ Treated group } & \multirow[t]{2}{*}{$\%$ Efficacy } & \multirow[t]{2}{*}{$p$-value } \\
\hline & $n$ & Geo mean (range) & $n$ & Geo mean (range) & & \\
\hline Lab \#1 & 8 & $226.6(16-2225)$ & 8 & $6.4(0-54)$ & 97.2 & $<0.001$ \\
\hline Lab \#2 & 10 & $65.1(4-630)$ & 10 & $0.1(0-1)$ & 99.9 & $<0.0001$ \\
\hline Field Study & 33 & $139.6(2-1548)$ & 32 & $3.7(0-136)$ & 97.4 & $<0.0001$ \\
\hline
\end{tabular}

Lab \#1: the live ear mite counts on Day 28 revealed adequate infestation of the untreated control cats, and a high level of efficacy in the treated group with $97.2 \%$ reduction $(0,0,1,2,26,27,34,54$ live mites were found in the eight cats of the treated group).

Lab \#2: the live ear mite counts on Day 32 revealed adequate infestation of the untreated control cats and a high level of efficacy in the treated group with $99.9 \%$ reduction (only one live mite was found in the ten cats of the treated group).

Field trial: The live ear mite counts on Day 30 revealed adequate infestation of the untreated control cats and a high level of efficacy in the treated group with $97.4 \%$ reduction (0-136 live mites were found in the 33 cats of the treated group).

\section{Ear canal otoscopical examinations}

None of these observations were supported by a statistical analysis and should be considered purely descriptive.

In Lab \#1, the results of otoscopical assessments are illustrated in Figures 1 and 2. The treatment effect was visible on the otoscopical semi-quantitative mite level assessment performed weekly for 1 month (Fig. 1). Overall, it remained unchanged in the placebo group; in the treated group, it had dropped to approximately a quarter of the baseline level on the first week after treatment and remained steady until the end of the month. The otoscopical semi-quantitative mite assessments in the treated group in comparison to mite counts following ear canal flushing (Table 3), show that quantification of ear mites by otoscopy is relevant, however less accurate, especially by its limitation to reflect high numbers of ear mites (no statistical analyses were performed to compare the two methods).

The treatment effect was visible on the debris/cerumen scoring (Fig. 2). Over the month of the study, the overall level of cerumen/debris had slightly increased in the placebo group, while it had approximately halved in the novel formulation-treated group.

In the Field study, the course of otitis signs between Day 0 and Day 30 is described in Table 4. One month after treatment,

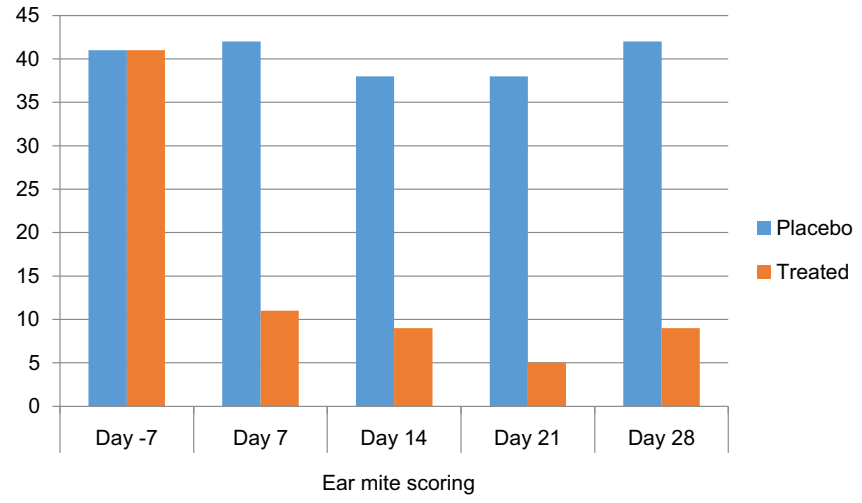

Figure 1. Ear mite otoscopical scoring in Lab \#1. Sum of individual otoscopical scores of live mites inclusive of both ears of each cat per group $(n=8)$.

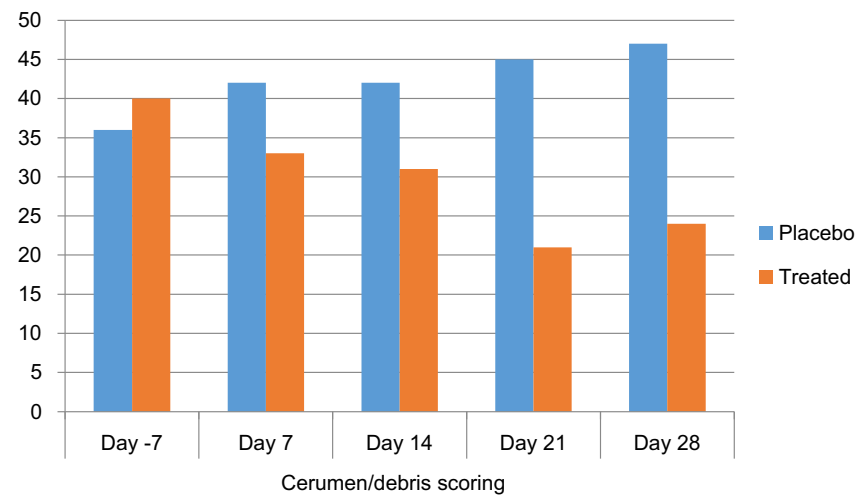

Figure 2. Debris/cerumen scoring in Lab \#1. Sum of individual otoscopical scores of debris/cerumen inclusive of both ears of each cat per group $(n=8)$.

in the novel formulation-treated group, the debris/cerumen level had improved in a majority of cats (28 of 32) and had cleared in a third of the cats (10 of 32); the pruritus level had improved in a majority of cats (27 of 32), and had cleared in half the cats (17 of 32). In the untreated control group, the otitis signs 
Table 4. Course of otitis signs in the Field study, one month after treatment

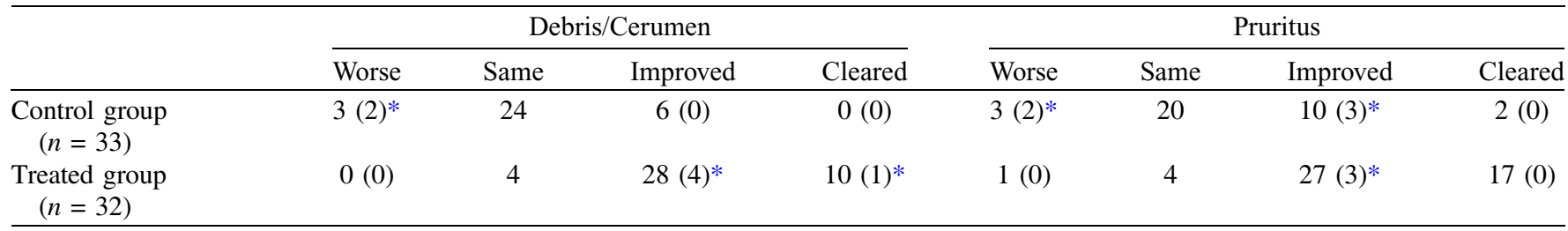

Worse: otoscopical scoring was higher on Day 30 than on Day 0.

Same: otoscopical scoring for both ears was identical on Days 0 and 30.

Improved: otoscopical scoring was lower on Day 30 than on Day 0.

Cleared: otoscopical scoring was 0 .

* In brackets = number of cats for which only one ear improved, worsened or cleared.

remained the same in about two third of the cats, other cats improved, and a smaller number worsened.

\section{Discussion and conclusions}

The results of these three studies provide a robust demonstration of the high level of efficacy of NexGard ${ }^{\circledR}$ Combo for the treatment of $O$. cynotis infestations, in induced and natural infestation models in laboratory and field studies, in Europe, the United States, and South Africa, with efficacy results of a single treatment exceeding $97 \%$ each time.

It was observed and confirmed in the untreated cats that the level of infestation in ear mite infested cats is highly variable and can range from a few acarians to several hundred per ear canal, without a clear or consistent intensity correlation with otitis signs [8], in natural or induced laboratory models, and in the field.

In Lab \#1 and the Field study, the studies with highest infestation levels, even though treatment efficacy was demonstrated, some of the treated cats still had a significant number of mites in their ear canals one month after treatment. The lifecycle of $O$. cynotis is 18-28 days [33], meaning that all development forms of the parasite had been exposed to the acaricide compound in the treated groups before mite collection. It is, nevertheless, unclear whether the full $O$. cynotis development cycle was broken for most infested cats of the group, and whether the observed live mites had survived the acaricide treatment over the month or were new mites from unkilled eggs hatching near the end of the month, and whether these live mites would have survived and started a new cycle or died later. The otitis signs observed in these two studies confirm that the novel formulation treatment provided a clear improvement of clinical signs; however, their level of improvement was not as high as the measured elimination of mites. In the absence of studies verifying the effect of a single treatment with the novel formulation over a period exceeding one month, it might be advisable to administer a second treatment after one month for highly infested cats, or for cats for which otitis signs had not fully cleared one month after treatment.

This novel association of esafoxolaner, eprinomectin and praziquantel offers a broad spectrum of efficacy against the main parasites of cats including ecto- and endoparasites [15, 21, 29-31]. The control of multiple and various concurrent parasitic infestations by a range of cat parasites is important for cats but also for public health $[2,11,32]$. Co-infestation of ectoparasites and endoparasites was demonstrated in $14 \%$ of 1519 cats and $O$. cynotis was the most prevalent ectoparasite $(17.4 \%)$ of cats [4]

In addition to a high level of efficacy and safety, owner and cat compliance is an important feature of success for this type of therapeutic approach, and the simple conditions of use and of treatment application of this product should guarantee a high level of compliance.

Acknowledgements. The authors would like to thank staff at Cheri-Hill and at Clinvet International for running the experimental studies to high professional standards, as well as the veterinarians who supported the study to high professional standards in Hungary and in Greece: Panagiotidou Agapi, Limpanobnou Asimina, Dafereras Markos, Mantzios Dimitris and Memmou Irini.

\section{Competing interest}

The work reported herein was funded by BoehringerIngelheim. The authors are current employees of BoehringerIngelheim Animal Health or external organizations. Other than that, the authors declare no conflict of interest. This document is provided for scientific purposes only. Any reference to a brand or trademark herein is for information purposes only and is not intended for any commercial purposes or to dilute the rights of the respective owners of the brand(s) or trademark(s). NexGard ${ }^{\circledR}$ is a registered trademark of the Boehringer Ingelheim Group.

\section{References}

1. Becskei C, Reinemeyer C, King VL, Lin D, Myers MR, Vatta AF. 2017. Efficacy of a new spot-on formulation of selamectin plus sarolaner in the treatment of Otodectes cynotis in cats. Veterinary Parasitology, 238, 27-30.

2. Beugnet F, Marié JL. 2009. Emerging arthropod-borne diseases of companion animals in Europe. Veterinary Parasitology, 163, 298-305.

3. Beugnet F, Franc M. 2012. Insecticide and acaricide molecules and/or combinations to prevent pet infestation by ectoparasites. Trends in Parasitology, 28, 267-279.

4. Beugnet F, Bourdeau P, Chalvet-Monfray K, Cozma V, Farkas R, Guillot J, Halos L, Joachim A, Losson B, Miró G, Otranto D, Renaud M, Rinaldi L. 2014. Parasites of domestic 
owned cats in Europe: co-infestations and risk factors. Parasites \& Vectors, 7, 291.

5. Beugnet F, Boushira E, Halos L, Franc M. 2014. Preventive efficacy of a topical combination of fipronil - (S)-methoprene eprinomectin - praziquantel against ear mite (Otodectes cynotis) infestation of cats through a natural infestation model. Parasite, $21,40$.

6. Beugnet F, de Vos C, Liebenberg J, Halos L, Larsen D, Fourie J. 2016. Efficacy of afoxolaner in a clinical field study in dogs naturally infested with Sarcoptes scabiei. Parasite, 23, 26.

7. Beugnet F, Halos L, Larsen D, de Vos C. 2016. Efficacy of oral afoxolaner for the treatment of canine generalised demodicosis. Parasite, 23, 14.

8. Bowman A. 2014. Otodectes cynotis. https://www.aavp.org.

9. Carithers D, Crawford J, de Vos C, Lotriet A, Fourie J. 2016. Assessment of afoxolaner efficacy against Otodectes cynotis infestations of dogs. Parasites \& Vectors, 9, 635.

10. Curtis CF. 2004. Current trends in the treatment of Sarcoptes, Cheyletiella and Otodectes mite infestations in dogs and cats. Veterinary Dermatology, 15, 108-114.

11. Deplazes P, van Knapen F, Schweiger A, Overgaauw PA. 2011. Role of pet dogs and cats in the transmission of helminthic zoonoses in Europe, with a focus on echinococcosis and toxocarosis. Veterinary Parasitology, 182, 41-53.

12. Fourie LJ, Kok DJ, Heine J. 2003. Evaluation of the efficacy of an imidacloprid $10 \%$ /moxidectin $1 \%$ spot-on against Otodectes cynotis in cats. Parasitological Research, 90(Suppl. 3), 112-113.

13. Griffin CE. 1993. Otitis externa and otitis media, in Current Veterinary Dermatology: The Science and Art of Therapy, Griffin CE, Kwochka KW, MacDonald JM, Editors. Mosby Year Book: St. Louis, Missouri. p. 245-262.

14. Hampel V, Knaus M, Schäfer J, Beugnet F, Rehbein S. 2018. Treatment of canine sarcoptic mange with afoxolaner (NexGard) and afoxolaner plus milbemycin oxime (NexGard Spectra) chewable tablets: efficacy under field conditions in Portugal and Germany. Parasite, 25, 63.

15. Knaus M, Baker C, Alva R, Mitchell E, Irwin J, Shukullari E, Veliu A, Ibarra-Velarde F, Liebenberg J, Reinemeyer C, Tielemans E, Wakeland K, Johnson C. 2021. Efficacy of a novel topical combination of esafoxolaner, eprinomectin and praziquantel in cats against Toxocara cati and Dipylidium caninum. Parasite, 28, 28.

16. Lebon W, Beccati M, Bourdeau $\mathrm{P}$, Brement $\mathrm{T}$, Bruet V, Cekiera A, Crosaz O, Darmon C, Guillot J, Mosca M, Pin D, Popiel J, Handwerker DP, Larsen D, Tielemans E, Beugnet F, Halos L. 2018. Efficacy of two formulations of afoxolaner $\left(\right.$ NexGard $^{\circledR}$ and NexGard Spectra $\left.{ }^{(}\right)$for the treatment of generalised demodicosis in dogs, in veterinary dermatology referral centers in Europe. Parasites \& Vectors, 11, 506.

17. Lefkaditis MA, Koukeri SE, Mihalca AD. 2009. Prevalence and intensity of Otodectes cynotis in kittens from Thessaloniki area, Greece. Veterinary Parasitology, 163, 374-375.

18. Machado MA, Campos DR, Lopes NL, Barbieri Bastos IP, Botelho CB, Correia TR, Scott FB, Fernandes JI. 2018. Efficacy of afoxolaner in the treatment of otodectic mange in naturally infested cats. Veterinary Parasitology, 256, 29-31.

19. Medleau L, Hnilica K. 2006. Parasitic skin diseases in Small Animal Dermatology, 2nd edn. St. Louis, Missouri: Saunders Elsevier, (5). p. 99-138.
20. Perego R, Proverbio D, Bagnagatti De Giorgi G, Della Pepa A, Spada E. 2013. Prevalence of otitis externa in stray cats in northern Italy. Journal of Feline Medicine and Surgery, 16, 483-490.

21. Prullage J, Pfefferkorn A, Knaus M, Frost J, Mitchell E, Wang H, Tielemans E. 2021. Efficacy of a novel topical combination of esafoxolaner, eprinomectin and praziquantel against Ixodes ricinus and Ixodes scapularis in cats. Parasite, 28, 23.

22. Roy J, Bédard C, Moreau M. 2011. Treatment of feline otitis externa due to Otodectes cynotis and complicated by secondary bacterial and fungal infections with Oridermyl auricular ointment. Canadian Veterinary Journal, 52(3), 277-282.

23. Russell R, Otranto D, Wall R. 2013. Mites in the Encyclopedia of Medical and Veterinary Entomology. Oxfordshire: CABI. p. 209-242.

24. Shanks DJ, McTier TL, Rowan TG, Watson P, Thomas CA, Bowman DD, Hair JA, Pengo G, Genchi G, Smothers CD, Smith DG, Jernigan AD. 2000. The efficacy of selamectin in the treatment of naturally acquired aural infestations of Otodectes cynotis on dogs and cats. Veterinary Parasitology, 91, 283-290.

25. Six RH, Clemence RG, Thomas CA, Behan S, Boy MG, Watson P. 2000. Efficacy and safety of selamectin against Sarcoptes scabiei on dogs and Otodectes cynotis on dogs and cats presented as veterinary patients. Veterinary Parasitology, 91, 291-309.

26. Six RH, Becskei C, Mazaleski MM, Fourie JJ, Mahabir SP, Myers MR, Slootmans N. 2016. Efficacy of sarolaner, a novel oral isoxazoline, against two common mite infestations in dogs: Demodex spp. and Otodectes cynotis. Veterinary Parasitology, $222,62-66$.

27. Sotiraki ST, Koutinas AF, Leontides LS, Adamama-Moraitou KK, Himonasa CA. 2001. Factors affecting the frequency of ear canal and face infestation by Otodectes cynotis in the cat. Veterinary Parasitology, 96, 309-315.

28. Taenzler J, de Vos C, Roepke RKA, Heckeroth AR. 2018. Efficacy of fluralaner plus moxidectin (Bravecto ${ }^{\circledR}$ Plus spot-on solution for cats) against Otodectes cynotis infestations in cats. Parasites \& Vectors, 11, 595.

29. Tielemans E, Buellet P, Prullage J, Young D, Viljoen A, Liebenberg J, Wang H. 2021. Efficacy of a novel topical combination of esafoxolaner, eprinomectin and praziquantel against adult cat flea Ctenocephalides felis and flea egg production in cats. Parasite, 28, 21.

30. Tielemans E, Pfefferkorn A, Viljoen A. 2021. Efficacy of a novel topical combination of esafoxolaner, eprinomectin and praziquantel against Rhipicephalus sanguineus in cats. Parasite, $28,24$.

31. Tielemans E, Otsuki T, Cheesman T, Selmes F, Pfefferkorn A, Prullage J. 2021. Efficacy of a novel topical combination of esafoxolaner, eprinomectin and praziquantel against fleas in cats, under field conditions. Parasite, 28, 22.

32. Traversa D. 2012. Pet roundworms and hookworms: a continuing need for global worming. Parasites \& Vectors, 5, 91-110.

33. Wall R, Shearer D, Editors. 2001. Veterinary ectoparasites: biology, pathology and control, 2nd edn. Hoboken: WileyBlackwell.

Cite this article as: Tielemans E, Prullage J, Tomoko O, Liebenberg J, Capári B, Sotiraki S, Kostopoulou D, Ligda P, Ulrich M \& Knaus M. 2021. Efficacy of a novel topical combination of esafoxolaner, eprinomectin and praziquantel against ear mite (Otodectes cynotis) infestations in cats. Parasite 28, 26. 
An international open-access, peer-reviewed, online journal publishing high quality papers on all aspects of human and animal parasitology

Reviews, articles and short notes may be submitted. Fields include, but are not limited to: general, medical and veterinary parasitology; morphology, including ultrastructure; parasite systematics, including entomology, acarology, helminthology and protistology, and molecular analyses; molecular biology and biochemistry; immunology of parasitic diseases; host-parasite relationships; ecology and life history of parasites; epidemiology; therapeutics; new diagnostic tools.

All papers in Parasite are published in English. Manuscripts should have a broad interest and must not have been published or submitted elsewhere. No limit is imposed on the length of manuscripts.

Parasite (open-access) continues Parasite (print and online editions, 1994-2012) and Annales de Parasitologie Humaine et Comparée (1923-1993) and is the official journal of the Société Française de Parasitologie. 